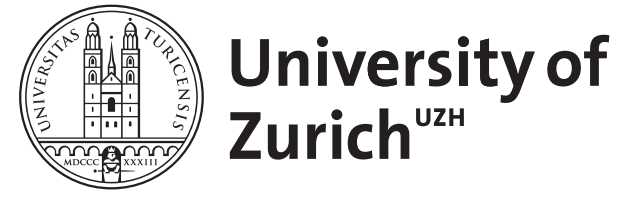

Zurich Open Repository and Archive

University of Zurich

University Library

Strickhofstrasse 39

CH-8057 Zurich

www.zora.uzh.ch

Year: 2007

\title{
Antimicrobial agents targeting the ribosome: the issue of selectivity and toxicity - lessons to be learned
}

Böttger, E C

DOI: https://doi.org/10.1007/s00018-007-6431-5

Posted at the Zurich Open Repository and Archive, University of Zurich ZORA URL: https://doi.org/10.5167/uzh-4539

Journal Article

Published Version

Originally published at:

Böttger, E C (2007). Antimicrobial agents targeting the ribosome: the issue of selectivity and toxicity lessons to be learned. Cellular and Molecular Life Sciences, 64(7-8):791-795.

DOI: https://doi.org/10.1007/s00018-007-6431-5 


\title{
Visions \& Reflections (Minireview)
}

\section{Antimicrobial agents targeting the ribosome: the issue of selectivity and toxicity - lessons to be learned}

\author{
E. C. Böttger \\ Institut für Medizinische Mikrobiologie, Universität Zürich, Gloriastrasse 30/32, CH-8006 Zürich \\ (Switzerland), Fax: +41446344906, e-mail: boettger@immv.unizh.ch
}

Received 28 September 2006; received after revision 15 November 2006; accepted 8 January 2007

Online First 13 February 2007

Keywords. Drugs, ribosome, crystallography, genetics, toxicity.

Many of the compounds that are used in clinical medicine for treatment of infectious diseases interfere with protein synthesis by targeting the ribosome [1], e.g., macrolides, ketolides, lincosamides, oxazolidinones, aminoglycosides, and tetracyclines. In general, antibiotics target the ribosome at locations of functional relevance, e.g., decoding, translocation, and peptidyl transfer. The increasing incidence of antibiotic resistance and the toxicity associated with some of the available agents constitute a formidable challenge for further exploitation of the ribosome as a drug target.

The principle of antimicrobial chemotherapy dates back to Paul Ehrlich's concept of selective toxicity. The ribosome is a highly conserved structure present in all three kingdoms of life: archea, bacteria, and eukaryotes. How can ribosomal inhibitors fulfil the principle of selective toxicity? Drugs targeting the ribosome are characterized by two features: specificity (see Table 1) and toxicity. Ribosomal inhibitors, which are used in clinical medicine for treatment of infectious diseases, exhibit varying degrees of toxicity. Macrolides and lincosamides show very little toxicity, if any, while the therapeutic use of aminoglycosides is limited by significant ototoxicity and nephrotoxicity. How to explain these different degrees of toxicity? What is the basis for drug selectivity?

The ribosome is a complex macromolecular structure which consists of a large and a small subunit. These two subunits are composed of dozens of different proteins, and nucleic acids, termed rRNA. During the past decades, considerable evidence has accumulated demonstrating that the nucleic acid component of the ribosome is key to binding many of the ribosomal drugs, rather than the numerous ribosomal proteins [1-3]. Recent data from X-ray crystallography have not only confirmed this suggestion but also provided details of drug-target interactions at the atomic level by revealing how antibiotic binding occurs [4-8].

The eukaryotic ribosome comes in two flavors: the cytoplasmic and the mitochondrial ribosome. The components of the cytoribosome are encoded by chromosomal genes as are the mitoribosomal proteins. However, the rRNA components of the mitoribosome are encoded by the mitochondrial genome (www.mitomap.org). Although the basis for drugrelated toxicity of the ribosomal inhibitors is unknown, several lines of evidence point to mitoribosomes as the Achilles heel of ribosomal antibiotics, because: (i) mitochondrial ribosomes are more related to the prokaryotic ribosome than to the eukaryotic cytoplasmic ribosome; (ii) toxicity in vivo correlates with activity in vitro, i.e., those antibiotics which exhibit in vitro activity on mitoribosomes are associated with toxicity in vivo; (iii) familial hypersensitivity to aminoglycosides (drug-induced deafness) is associated with specific mutations in mitochondrial rRNA [9].

Investigations on and genetic manipulations of ribo- 
Table 1. Ribosomal specificity of selected antibiotics ${ }^{\mathrm{a}}$

\begin{tabular}{ll}
\hline $\mathbf{7 0 S}$ & $\mathbf{8 0 S}$ \\
Aminoglycosides & Cycloheximide \\
Macrolides & \\
Ketolides & \\
Lincosamides & \\
Streptogramins & $\mathbf{7 0 S} / \mathbf{8 0 S}$ \\
$\begin{array}{l}\text { Oxazolidinones } \\
\text { Spectinomycin }\end{array}$ & Hygromycin \\
Chloramphenicol & Sparsomycin \\
Capreomycin & \\
\hline a $70 S=$ prokaryotic (bacterial) ribosome, $80 \mathrm{~S}=$ eukaryotic ribo- \\
some
\end{tabular}

somal nucleic acids are problematic, because most eubacteria harbor multiple rRNA operons in their chromosome. For many of the antibiotics targeting the ribosome, susceptibility is dominant over resistance [10]. Thus, a merodiploid strain with a mutant resistant allele and a wild-type susceptible allele usually exhibits a drug-susceptible phenotype. As the majority of eubacteria are characterized by the presence of multiple rRNA ( $\mathrm{rr}$ ) operons, resistanceconferring alterations in $r r n$ were initially rarely described in clinical pathogens. In the mid 1990s mutations in rRNAs were first recognized as a significant cause of acquired drug resistance in major clinical pathogens [11-18]. Subsequently, genetic procedures were developed which permitted the construction of eubacteria carrying a single functional rRNA operon [15, 19]. These single rRNA allelic microorganisms allow mutagenesis of their ribosomal nucleic acids to result in cells containing homogeneous populations of mutant ribosomes. Genetic, biochemical, and structural studies have provided a detailed picture of the importance of specific nucleotides for high-affinity binding of ribosomal drugs to their respective rRNA target site.

Clinically useful ribosomal antibiotics must discriminate between bacterial and eukaryotic ribosomes. The high cross-species conservation of functional sites within the ribosomal RNA, targeted by ribosomal drugs, implies limitations with respect to selectivity. In the case of aminoglycosides, bacterial and mitochondrial ribosomes are susceptible, while eukaryotic cytoplasmic ribosomes are insensitive to these drugs. In contrast, while bacterial ribosomes are susceptible to macrolide antibiotics, both the mitochondrial and the eukaryotic cytoplasmic ribosome are naturally resistant to these agents [20].

It has been suggested that the analysis of drug resistance mutations in bacteria allows one to understand the basis of specificity for drugs targeting the ribosome [21]. Central to this hypothesis is the concept of 'informative sequence positions' - i.e., the identification of polymorphic nucleotides as a determinant of ribosomal resistance. The identification of a polymorphic residue as determinant of ribosomal resistance provides information about the selectivity of a ribosomal antibiotic, i.e., why a drug affects the prokaryotic as opposed to the eukaryotic ribosome (see Table 2). The basis for this hypothesis was initially established by investigating bacterial alterations within the ribosome mediating resistance to aminoglycosides and macrolides. The conclusion from these studies was that the selectivity of these agents is largely due to a single nucleotide position within the rRNA, e.g., the identity of the base at $16 \mathrm{~S}$ rRNA position 1408 determines selectivity of aminoglycosides, while the identity of the base at 23S rRNA position 2058 determines the selectivity of macrolides [21]. For aminoglycosides, selectivity is due to the natural insensitivity of eukaryotic cytoplasmic ribosomes conferred by a guanine at $16 \mathrm{~S}$ rRNA position 1408; the toxicity of aminoglycosides (at least irreversible ototoxicity) is due to the natural susceptibility of mitoribosomes, which carry a susceptible bacterial adenine at this sequence position. Macrolides are characterized by the virtual absence of target-related toxicity; both cytoribosomes and mitoribosomes are naturally resistant to these drugs, with resistance conferred by a guanine at $23 \mathrm{~S}$ rRNA position 2058 (Table 2).

In an effort to challenge this concept, a single rRNA allelic eubacterium was saturated with drug-resistance-conferring mutations by selecting for spontaneous resistance to hygromycin $\mathrm{B}$, a universal inhibitor of translation. If a polymorphic rRNA residue had been found to confer resistance, this would have effectively falsified the concept. All of the resistance mutations were found to map to the hygromycinbinding site within helix 44 of 16S rRNA. Significantly, analysis of drug-resistance-conferring rRNA mutations revealed that these were restricted to universally conserved nucleotides [28] (Table 2, Fig. 1). The observation that ribosomal alterations mediating resistance by hygromycin B exclusively involve universally conserved nucleotides within rRNA explains the lack of specificity and general toxicity of hygromycin B.

Linezolid is a representative of a new class of antibiotics, the oxazolidinones. These drugs inhibit protein synthesis, both in vivo and in vitro, and have activity against a wide range of Gram-positive and Gram-negative bacteria [30]. Linezolid binds to the large ribosomal subunit, and its binding site on the $23 \mathrm{~S}$ rRNA overlaps with that of the peptidyl transferase inhibitor chloramphenicol [31]. Early on, linezolid 
Table 2. Bacterial resistance mutations and corresponding eukaryotic sequence positions

\begin{tabular}{|c|c|c|c|c|c|}
\hline \multirow[t]{2}{*}{ Drug } & \multirow{2}{*}{$\begin{array}{l}\text { rRNA } \\
\text { position }\end{array}$} & \multicolumn{2}{|l|}{ Eubacteria } & \multicolumn{2}{|l|}{ Eukaryotes } \\
\hline & & susceptible & resistant & mitochondrial & cytoplasmic \\
\hline \multirow{5}{*}{$\begin{array}{l}\text { Macrolides } \\
\text { (e.g., clarithromycin, azithromycin, } \\
\text { erythromycin) }\end{array}$} & 2058 & A & $\mathrm{G}[22]$ & $\mathbf{G}$ & $\mathbf{G}$ \\
\hline & & & $\begin{array}{l}C[22] \\
U[22]\end{array}$ & & \\
\hline & 2059 & A & $\mathrm{G}[22]$ & A & A \\
\hline & & & $\mathrm{C}[22]$ & & \\
\hline & $2057 / 2611$ & $\begin{array}{l}\text { base pairing } \\
(\mathrm{A}-\mathrm{U}, \mathrm{G}-\mathrm{C})\end{array}$ & $\begin{array}{l}\text { disruption of base paring } \\
\text { [23] }\end{array}$ & $\mathrm{A}-\mathrm{U}$ & $\mathrm{A}-\mathrm{U}$ \\
\hline $\begin{array}{l}\text { Lincosamides } \\
\text { (e.g., clindamycin) }\end{array}$ & 2058 & A & $\begin{array}{l}\mathrm{G}[24] \\
\mathrm{U}[24]\end{array}$ & $\mathbf{G}$ & $\mathbf{G}$ \\
\hline \multirow{7}{*}{$\begin{array}{l}\text { Aminoglycosides } \\
\text { (4,6-deoxy-streptamines with a } 6^{\prime} \mathrm{NH}_{3} \text { group; } \\
\text { e.g., gentamicin, tobramycin, kanamycin) }\end{array}$} & 1408 & A & $\mathrm{G}[15]$ & A & $\mathbf{G}$ \\
\hline & 1406 & $\mathrm{U}$ & $\mathrm{A}[25]$ & $\mathrm{U}$ & $\mathrm{U}$ \\
\hline & & & $\mathrm{C}[25]$ & & \\
\hline & 1495 & $\mathrm{U}$ & $\mathrm{A}[25]$ & $\mathrm{U}$ & $\mathrm{U}$ \\
\hline & 1491 & G & C (low level) $[26,27]$ & $\mathrm{C}$ & $\mathrm{A}^{1}$ \\
\hline & & & $\mathrm{U}$ (low level) [26, 27] & & \\
\hline & 1409 & $\mathrm{C}$ & G (low level) [26, 27] & $\mathrm{C}$ & $\mathrm{C}$ \\
\hline \multirow[t]{3}{*}{ Hygromycin B } & 1406 & $\mathrm{U}$ & $\mathrm{C}[28]$ & $\mathrm{U}$ & $\mathrm{U}$ \\
\hline & 1496 & $\mathrm{C}$ & $\mathrm{U}[28]$ & $\mathrm{C}$ & $\mathrm{C}$ \\
\hline & 1498 & $\mathrm{U}$ & $\mathrm{C}[28]$ & $\mathrm{U}$ & $\mathrm{U}$ \\
\hline
\end{tabular}

${ }^{1}$ Alteration of $1491 \mathrm{G}$ to A does not confer resistance [26, 27].
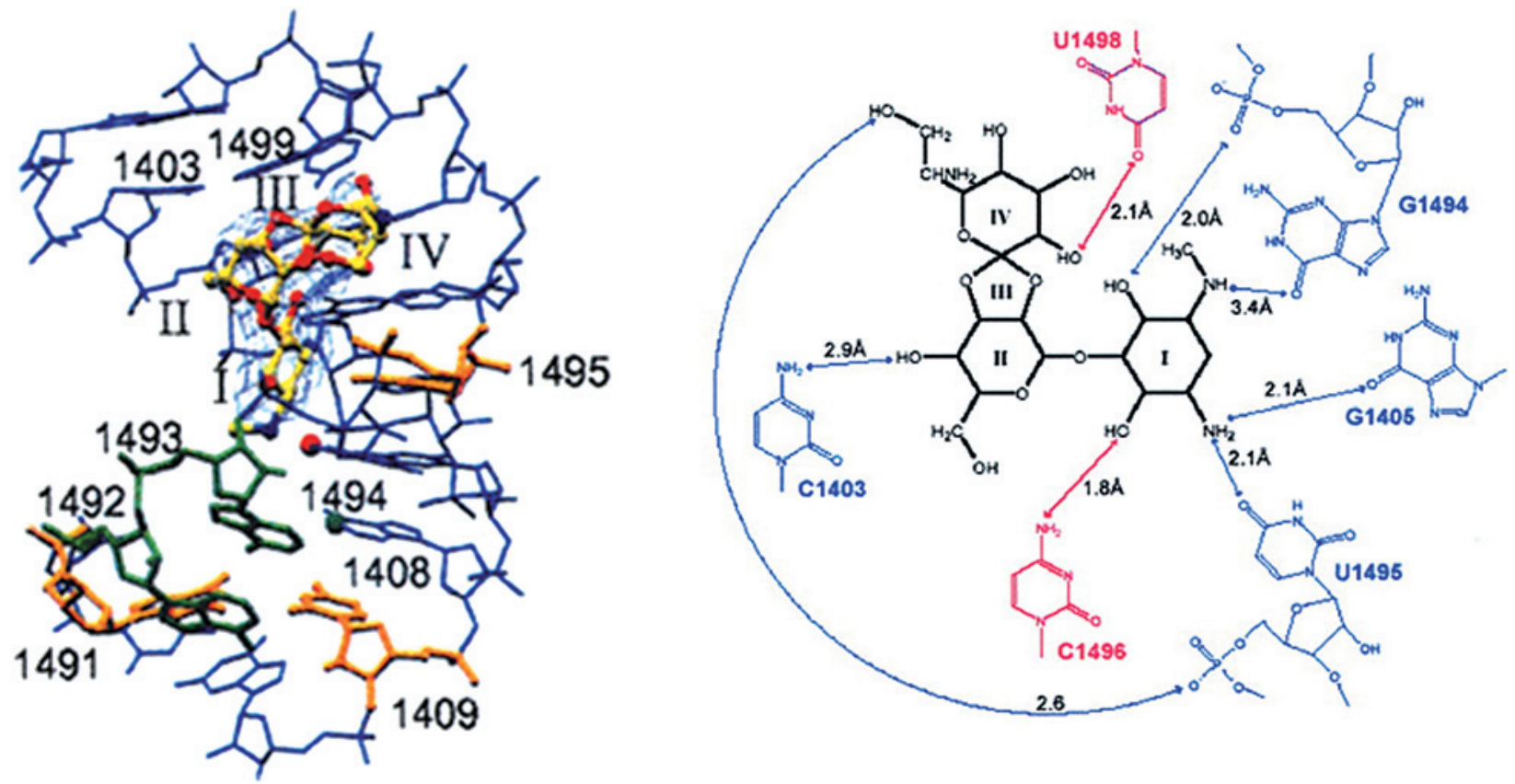

Figure 1. Overview of the hygromycin-binding site along with rRNA elements close to the site. Hygromycin B with rings I, II, III, and IV bound to helix 44 of 16S rRNA (left); rRNA elements close to the site (right). From Brodensen et al. [29], with permission from the publisher.

was found to be associated with high rates of adverse reactions, in particular myelosuppression and neuropathy [32, 33, for review, see ref. 34]. Clinically acquired and laboratory-selected resistance were found to be associated with mutations in 23S rRNA domain V [35-39]. In an effort to characterize the selectivity of the drug, we analyzed the described bacterial resistance mutations for genetic polymorphism, i.e. nucleotide positions mediating resistance which differ between the bacterial and the mitochondrial rRNA. Most of the resistance mediating nucleotide alterations were found to correspond to universally conserved positions, e.g., A2062, G2447, A2451, C2452, U2500, and G2505. However, rare positions 
corresponding to polymorphic nucleotides were identified, e.g., 23S rRNA positions 2032 (bacterial: G; mitochondrial: C) and 2513 (bacterial: G; mitochondrial: A), and introduced into a single rRNA allelic derivative of Mycobacterium smegmatis - none of the described resistance mutations was found to confer a linezolid-resistant phenotype [unpublished observations]. These findings suggest a pronounced speciesspecific bias in drug resistance mutations, a surprising finding for a broad-range ribosomal inhibitor. More importantly, these findings indicate the possibility that polymorphic nucleotide positions may not be involved in a more general mechanism of linezolid resistance, thus pointing to limitations in drug selectivity. These conclusions from genetic analyses of drug-resistant prokaryotes are corroborated by recent results revealing that oxazolidinones inhibit eukaryotic mitochondrial protein synthesis in vitro [40-42].

Substantial pharmaceutical resources have been invested in boosting the intrinsic affinity of oxazolidinones for the ribosome, e.g., by chemical attachment of sparsomycin, a universal inhibitor of peptide bond formation [43]. However, as the selectivity of this bifunctional compound relies entirely on the oxazolidinone part, this series of compounds will most likely be plagued by the same problems as linezolid: significant toxicity due to limited selectivity.

In general, the main problem in contemporary drug development is not activity, but toxicity. As far as the ribosome as drug target is concerned, the tools are available to characterize rapidly the selectivity of a compound for the bacterial versus eukaryotic (cytoplasmic, mitochondrial) ribosomes. The identification of a polymorphic rRNA residue as a resistancemediating residue nearly excludes target-related toxicity. Together with identification of functionally relevant sites in the ribosome [44], X-ray crystallography [4-8], and powerful chemistry, genetics is back at the core of drug development.

Acknowledgements. I apologize to all colleagues whose contributions could not be cited due to space limitations. Being trained primarily as a microbiologist and geneticist, I am particularly thankful to all colleagues from the fields of biochemistry, crystallography, and chemistry with whom I have had the privilege to collaborate. I am indebted to my co-workers with whom I have enjoyed a most stimulating environment during the past years and to the reviewers for their most constructive criticism and helpful comments. Work in my laboratory has been supported by the German Research Council (DFG), the Swiss National Science Foundation (SNF) and the European Commission.

1 Gale, E.F., Cundliffe, E., Reynolds, P.E., Richmond, M.H. and Waring, M.J. (1981) The Molecular Basis of Antibiotic Action, 2nd edn. Wiley, London.

2 Moazed, D. and Noller, H.F. (1987) Interaction of antibiotics with functional sites in 16 S ribosomal RNA. Nature 327, $389-$ 394.
3 Noller, H.F. (1991) Ribosomal RNA and translation. Annu. Rev. Biochem. 60, 191 - 227.

4 Ban, N., Nissen, P., Hansen, J., Moore, P.B. and Steitz, T.A. (2000) The complete atomic structure of the large ribosomal subunit at 2.4 A resolution. Science 289, $905-920$.

5 Wimberly, B.T., Brodersen, D.E., Clemons, W.M. Jr., MorganWarren, R.J., Carter, A.P., Vonrhein, C., Hartsch, T. and Ramakrishnan, V. (2000) Structure of the 30S ribosomal subunit. Nature 407, $327-339$.

6 Harms, J., Schluenzen, F., Zarivach, R., Bashan, A., Gat, S., Agmon, I., Bartels, H., Franceschi, F. and Yonath, A. (2001) High resolution structure of the large ribosomal subunit from a mesophilic eubacterium. Cell 107, 679-688.

7 Yusupov, M.M., Yusupova, G. Zh., Baucom, A., Lieberman, K., Earnest, T.N., Cate, J.H.D. and Noller, H.F. (2001) Crystal structure of the ribosome at $5.5 \AA$ resolution. Science 292, $883-896$.

8 Schuwirth, B.S., Borovinskaya, M.A., Hau, C.W., Zhang, W., Vila-Sanjurjo, A., Holton, J.M. and Doudna Cate, J.H. (2005) Structures of the bacterial ribosome at $3.5 \AA$ resolution. Science 310, $827-834$.

9 Prezant, T.R., Agapian, J.V., Bohlmann, M.C., Bu, X., Öztas, S., Qiu, W.Q., Arnos, K.S., Cortopassi, G.A., Jaber, L., Rotter, J.I., Shohat, M. and Fischel-Ghodsian, N. (1993) Mitochondrial ribosomal RNA mutation associated with both antibioticinduced and non-syndromic deafness. Nat. Genet. 4, 289 - 294.

10 Prammananan, T., Sander, P., Springer, B. and Böttger, E.C. (1999) RecA-mediated gene conversion and aminoglycoside resistance in strains heterozygous for rRNA. Antimicrob. Agents Chemother. 43, $447-453$.

11 Finken, M., Kirschner, P., Meier, A., Wrede, A. and Böttger, E.C. (1993) Molecular basis of streptomycin resistance in Mycobacterium tuberculosis, alterations of the ribosomal protein S12 gene and point mutations within a functional 16S ribosomal RNA pseudoknot. Mol. Microbiol. 9, 1239 - 1246.

12 Prammananan, T., Sander, P., Brown, B.A., Frischkorn, K., Onyi, G.O., Zhang, Y., Böttger, E.C. and Wallace, R.J. Jr. (1998) A single 16S ribosomal RNA substitution is responsible for resistance to amikacin and other 2-deoxystreptamine aminoglycosides in Mycobacterium abscessus and Mycobacterium chelonae. J. Infect. Dis. $177,1573-1581$.

13 Meier, A., Kirschner, P., Springer, B., Steingrube, V.A., Brown, B.A., Wallace, R.J. Jr. and Böttger, E.C. (1994) Identification of mutations in 23S rRNA gene of clarithromycin-resistant Mycobacterium intracellulare. Antimicrob. Agents Chemother. $38,381-384$.

14 Meier, A., Heifets, L., Wallace, R.J. Jr., Zhang, Y., Brown, B.A., Sander, P. and Böttger, E.C. (1996) Molecular mechanisms of clarithromycin resistance in Mycobacterium avium, observation of multiple $23 \mathrm{~S}$ rDNA mutations in a clonal population. J. Infect. Dis. 174, 354 - 360.

15 Sander, P., Prammananan, T. and Böttger, E.C. (1996) Introducing mutations into a chromosomal rRNA gene using genetically modified eubacterial host with a single rRNA operon. Mol. Microbiol. 22, 841 - 848 .

16 Wallace, R.J. Jr., Meier, A., Brown, B.A., Zhang, Y., Sander, P., Onyi, G.O. and Böttger, E.C. (1996) Genetic basis for clarithromycin resistance among isolates of Mycobacterium chelonae and Mycobacterium abscessus. Antimicrob. Agents Chemother. 40, $1676-1681$.

17 Versalovic, J., Shortridge, D., Kibler, K., Griffy, M.V., Beyer, J., Flamm, R.K., Tanaka, S.K. Graham, D.Y. and Go, M.F. (1996) Mutations in 23S rRNA are associated with clarithromycin resistance in Helicobacter pylori. Antimicrob. Agents Chemother. 40, 477 - 480.

18 Farrell, D.J., Douthwaite, S., Morrissey, I., Bakker, S., Poehlsgaard, J., Jakobsen, L. and Felmingham, D. (2003) Macrolide resistance by ribosomal mutation in clinical isolates of Streptococcus pneumoniae from the PROTEKT 1999 - 2000 study. Antimicrob. Agents Chemother. 47, 1777-1783.

19 Asai, R., Zaporojets, D., Squires, C. and Squires, C.L. (1999) An Escherichia coli strain with all chromosomal rRNA operons 
inactivated, complete exchange of rRNA genes between bacteria. Proc. Natl. Acad. Sci. USA 96, 1971 - 1976.

20 Kurtz, D.I. (1974) Fidelity of protein synthesis with chicken embryo mitochondrial and cytoplasmic ribosomes. Biochemistry $13,572-577$.

21 Böttger, E.C., Springer, B., Prammananan, T., Kidan, Y. and Sander, P. (2001) Structural basis for selectivity and toxicity of ribosomal antibiotics. EMBO Rep. 2, 318 - 323.

22 Pfister, P., Jenni, S., Poehlsgaard, J., Thomas, A., Douthwaite, S., Ban, N. and Böttger, E.C. (2004) The structural basis of macrolide-ribosome binding assessed using mutagenesis of $23 \mathrm{~S}$ rRNA positions 2058 and 2059. J. Mol. Biol. 342, 1569 - 1581.

23 Douthwaite, S. and Aagaard, C. (1993) Erythromycin binding is reduced in ribosomes with conformational alterations in the 23S rRNA peptidyl transferase loop. J. Mol. Biol. 232, 725 731.

24 Poehlsgaard, J., Pfister, P., Böttger, E.C. and Douthwaite, S (2005) Molecular mechanisms by which rRNA mutations confer resistance to clindamycin. Antimicrob. Agents Chemother. $49,1553-1555$

25 Pfister, P., Hobbie, S., Vicens, Q., Böttger, E.C. and Westhof, E. (2003) The molecular basis for A-site mutations conferring aminoglycoside resistance, relationship between ribosomal susceptibility and X-ray crystal structures. Chembiochemistry $4,1078-1088$.

26 Pfister, P., Hobbie, S., Brull, C., Corti, N., Vasella, A., Westhof, E. and Böttger, E.C. (2005) Mutagenesis of 16S rRNA C1409 G1491 base-pair differentiates between $6{ }^{\prime} \mathrm{OH}$ and $6^{\prime} \mathrm{NH}_{3}{ }^{+}$ aminoglycosides. J. Mol. Biol. 346, 467 - 475.

27 Hobbie, S.N., Pfister, P., Brull, C., Westhof, E. and Böttger, E.C. (2005) Analysis of the contribution of individual substituents in 4,6-aminoglycoside-ribosome interaction. Antimicrob. Agents Chemother. 49, $5112-5118$.

28 Pfister, P., Risch, M., Brodersen, D.E. and Böttger, E.C. (2003) Role of 16S rRNA helix 44 in ribosomal resistance to hygromycin, B. Antimicrob. Agents Chemother. 47, 14961502.

29 Brodersen, D.E., Clemons, W.M. Jr., Carter, A.P., Morgan Warren, R.J., Wimberley, B.T. and Ramakrishnan, V. (200) The structural basis for the action of the antibiotics tetracycline, pactamycin, and hydromycin $\mathrm{B}$ on the $30 \mathrm{~S}$ ribosomal subunit. Cell 103, 1143 - 1154

30 Shinabarger, D. (1999) Mechanism of action of the oxazolidinone antibacterial agents. Exp. Opin. Invest. Drugs 8, 1195 1202.

31 Lin, A.H., Murray, R.W., Vidmar, T.J. and Marotti, K.R. (1997) The oxazolidinone eperezolid binds to the 50S ribosomal subunit and competes with binding of chloramphenicol and lincomycin. Antimicrob. Agents Chemother. 41, $2127-2131$

32 Lee, E., Burger, S., Shah, J., Melton, C., Mullen, M., Warren, F. and Press, R. (2003) Linezolid-associated toxic optic neuropathy, a report of 2 cases. Clin. Infect. Dis. 37, $1389-1391$.
33 Attassi, K., Hershberger, E., Alam, R. and Zervos, M.J. (2002) Thrombocytopenia associated with linezolid therapy. Clin. Infect. Dis. 34, 695 - 698

34 Bishop, E., Melvani, S., Howden, B.P. Charles, P.G.P. and Grayson, M.L. (2006) Good clinical outcomes but high rates of adverse reactions during linezolid therapy for serious infections: a proposed protocol for monitoring therapy in complex patients. Antimicrob. Agents Chemother. 50, 1599 - 1602.

35 Kloss, P., Xiong, L., Shinabarger, D.L. and Mankin, A.S. (1999) Resistance mutations in 23S rRNA identify the site of action of the protein synthesis inhibitor linezolid in the ribosomal peptidyl transferase center. J. Mol. Biol. 294, 93 - 101.

36 Xiong, L., Kloss, P., Douthwaite, S., Møller Andersen, N., Swaney, S., Shinabarger, D.L. and Mankin, A.S. (2000) Oxazolidinone resistance mutations in 23S rRNA of Escherichia coli reveal the central region of domain $\mathrm{V}$ as the primary site of drug action. J. Bacteriol. 182, 5325 - 5331.

37 Tsiodras, S., Gold, H.S. Sakoulas, G., Eliopoulos, G.M., Wennersten C, Venkataraman, L., Moellering, R.C. and Ferraro, M.J. (2001) Linezolid resistance in a clinical isolate of Staphlylococcus aureus. Lancet 358, $207-208$.

38 Prystowsky, J., Siddiqui, F., Chosay, J., Shinabarger, D.L., Millichap, J., Peterson, L.R. and Noskin, G.A. (2001) Resistance to linezolid: characterization of mutations in rRNA and comparison of their occurrences in vancomycin-resistant enterococci. Antimicrob. Agents Chemother. 45, 2154 - 2156.

39 Sander, P., Belova, L., Kidan, Y.G., Pfister, P., Mankin, A.S. and Böttger, E.C. (2002) Ribosomal and non-ribosomal resistance to oxazolidinones: species-specific idiosyncrasy of ribosomal alterations. Mol. Microbiol. 46, 1295 - 1304

40 Nagiec, E.C., Swaney, S.M., Chosay, J.G., Ross, D.E., Brieland, J.K. and Leach, K.L. (2005) Oxazolidinones inhibit cellular proliferation via inhibition of mitochondrial protein synthesis. Antimicrob. Agents Chemother. 49, 3896 - 3902.

41 De Vriese, A.S., Coster, R.V., Smet, J., Seneca, S., Lovering, A., Van Haute, L.L., Vanopdenbosch, L.J., Martin, J.J., Groote, C.C., Vandecasteele, S. and Boelaert, J.R. (2006) Linezolid-induced inhibition of mitochondrial protein synthesis. Clin. Infect. Dis. 42, $1111-1117$.

42 McKee, E.E., Ferguson, M., Bentley, A.T. and Marks, T.A. (2006) Inhibition of mammalian mitochondrial protein synthesis by oxazolidinones. Antimicrob. Agents Chemother. 50, $2042-2049$.

43 Franceschi, F. and Duffy, E.M. (2006) Structure-based drug design meets the ribosome. Biochem. Pharmacol. 71, 10161025.

44 Yassin, A., Fredrick, K. and Mankin, A.S. (2005) Deleterious mutations in small subunit ribosomal RNA identify functional sites and potential targets for antibiotics. Proc. Natl. Acad. Sci. USA $102,16620-16625$

\section{To access this journal online: http://www.birkhauser.ch/CMLS}

